Document downloaded from:

http://hdl.handle.net/10251/44538

This paper must be cited as:

Serrano Cruz, JR.; Margot, X.; Tiseira Izaguirre, AO.; García-Cuevas González, LM. (2013). Optimization of the inlet air line of an automotive turbocharger. International Journal of Engine Research. 14(1):92-104. doi:10.1177/1468087412449085.

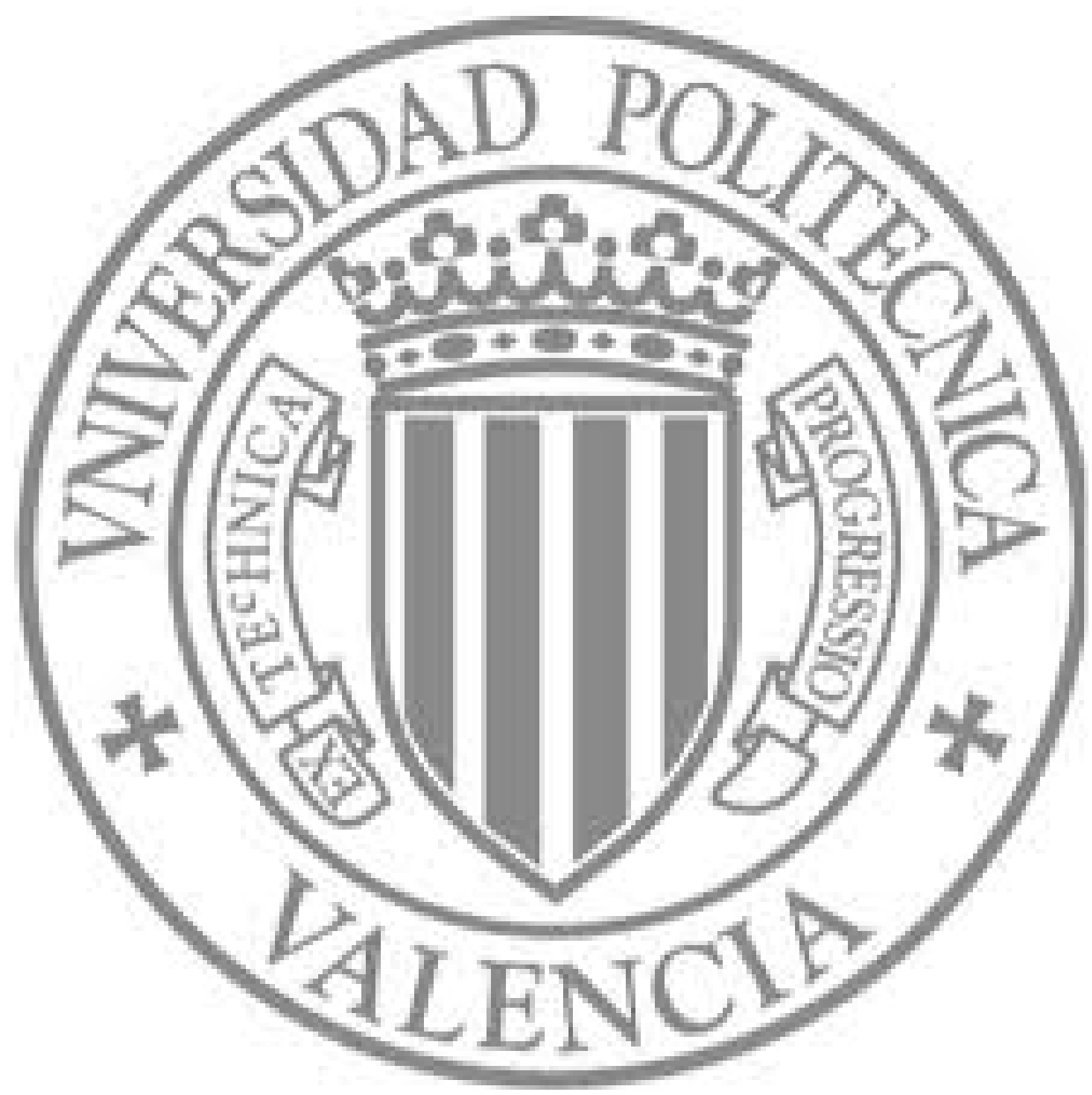

The final publication is available at

http://dx.doi.org/10.1177/1468087412449085

Copyright SAGE Publications (UK and US) 


\title{
Optimization of the Inlet Air Line of an Automotive Turbocharger.
}

\author{
Authors: \\ J.R. Serrano, A. Tiseira, X. Margot, L.M. García-Cuevas* \\ Universidad Politécnica de Valencia. CMT-Motores Térmicos. \\ Camino de Vera, s/n. 46022. Valencia, SPAIN. \\ *Corresponding author: \\ Phone: + 34963877650 \\ Fax: $\quad+34963877659$ \\ E-mail: luiga12@mot.upv.es
}

\begin{abstract}
This paper presents different aspects of air inlet behaviour near the inducer of a radial compressor and how the geometry can contribute to its stability and performance. Unfortunately the space reserved for installation of an automotive turbocharger in a vehicle is constantly being reduced, so it is necessary to study the effects that elbows and abrupt changes in flow directions originate on the compressor performance. The work presented in this paper studies the effect that different $90^{\circ}$ elbows have on the compressor with respect to its ideal, straight, no-elbow configuration, in order to obtain the best possible elbow configuration.
\end{abstract}

The methodology followed has been to, initially, study different geometries in CFD code in order to obtain the best possible configuration. Then, several $90^{\circ}$ elbows were constructed and characterised on a continuous flow test bench in order to validate the CFD results and to obtain optimum results. The elbows were then installed on a radial compressor and tested on a hot, continuous turbocharger test bench, where the compressor was characterised and maps were obtained with each different elbow. The results were compared with respect to the ideal, no-elbow configuration, which was taken as the base performance.

After analysing the results obtained, it is possible to observe that in most of the cases the elbows have a negative effect on the compression ratio, which tends to be reduced especially at high rotor velocities and high air mass flow. On the other hand, the effect on the surge limit seems to be positive, as the surge line shifts to lower air mass flows, although the maximum mass flow allowed is reduced. It seems as if the compressor map shifts to the left with a reduction in compression ratio. From theoretical and experimental study it has been concluded that flow uniformity index and pressure loss are the most important factors affecting the performance of the compressor. 


\section{Nomenclature}

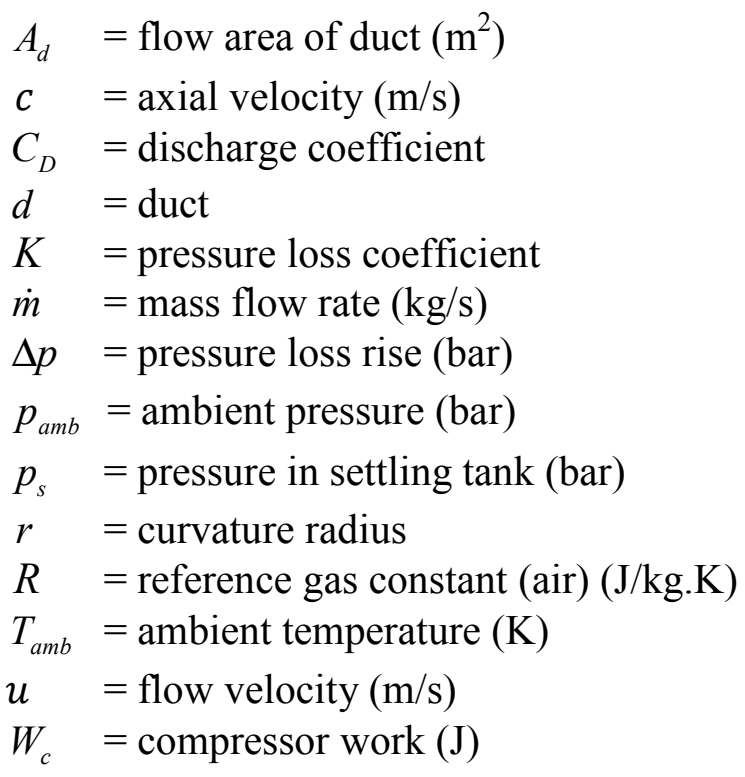

Greek symbols

$\rho \quad=$ density $\left(\mathrm{kg} / \mathrm{m}^{3}\right)$

$\lambda=$ angle of swirl

$\gamma \quad=$ ratio of heat capacities (1.4)

$\pi_{\mathrm{c}} \quad=$ compression ratio

$\eta \quad=$ efficiency

$\xi \quad=$ uniformity index

\section{Subscripts}

$$
\begin{array}{ll}
1 & =\text { compressor inlet } \\
2 & =\text { compressor outlet } \\
\mathrm{a} & =\text { axial }
\end{array}
$$

\section{Acronyms}

IC = Internal combustion

CFD = Computational fluid dynamics

FFT $=$ Fast Fourier Transform

Keyword: turbocharging compressor, inlet at $90^{\circ}$, depression, surge, uniformity, pressure drop

\section{Introduction}

Turbochargers have been in common use for at least the past 50 years to enhance the performance of internal combustion (IC) engines. Turbocharged diesel engines are standard and turbocharging is becoming increasingly widespread for spark ignition engines as well. This trend is set to continue with the ongoing drive for improved fuel 
economy and increasingly tight emissions legislation, where engine downsizing enabled by turbocharging is already playing a significant role.

A turbocharger is a machine which is mechanically separate from the IC engine and consists of a centrifugal compressor directly coupled to a radial turbine, which is driven by the, otherwise wasted, exhaust gases.

In normal engine operating conditions, surge had never been a problem as, traditionally, the compressor did not operate close to the surge line. But in recent years the demand for higher low engine speed torque, implies that high compressor pressure ratios are required at low mass flows. This translates in the compressor having to operate very close to the surge limit.

A simple solution to solve this problem would be to use a smaller compressor which could operate further away from the surge line at the required low mass flow. Unfortunately, a smaller compressor also translates into a lower maximum mass flow, as the compressor will choke earlier and would imply not being appropriate for the engine when operating at full load.

The admission line design can influence the compressor surge limit, which can be modified or affected by altering the inlet or outlet geometry of the compressor. According to White et al [1], the impossibility of placing the correct admission line when the compressor is installed on a vehicle can lead to significant problems, as the surge limit line will be different to the one determined by the manufacturer. An incorrect admission line can create great instability and non uniform flow at the inducer or blade leading edges, causing a phenomenon known as rotating stall which leads to compressor surge.

The literature reports that in the case of axial compressors they commonly exhibit rotating stall before surge [2]. The rotating stall not only depends on the compressor blade characteristics but also on the system in which it is installed and this is also extensive to the centrifugal compressors [3]. It is possible to consider the inlet distortions as the primary cause of the rotating stall phenomena as it is the main factor affecting the uniformity of the flow [4]. Surge and efficiency are known to be significantly influenced by the flow discharge characteristics on the impellers, which mainly depend on the behaviour of the airflow through the inducer [5]. Some distortions, evidenced in the flow, are caused by the elements that compose the inlet configuration line, inducing undesirable instabilities that reduce the compressor efficiency or produce compressor surge [6]. These distortions can be severe or light, but in any case they affect the compressor performance, so it is evidently important to study the inlet admission geometry line when a compressor is installed.

In recent years, when turbocharging the automotive Diesel engines, it is very common to find this type of problems in the inlet geometry compressor admission. This is due to the fact that the space reserved for the installation of the turbocharging system is being constantly reduced, mainly due to engine downsizing as well as due to the other auxiliary elements installed around the engine. Engine manufacturers want to pack everything together and make engines as compact as possible in order to reduce space, weight and cost. Turbocharger manufacturers usually proportionate compressor maps measured in turbocharger test benches with long and straight admission ducts and this 
information is used later by engine manufacturers in their computational models. This codes are used to study control strategies, being very important to assure that the compressor always works safely far from the surge line, as seen in [12] and [13]. As we will see, the influence of the geometry of the admission duct may be of high importance and should be taken into account by modifications of the compressor map and some elements that simulate the pressure losses. In the first stages of development of new engines is also usual to select a compressor using manufacturer's maps, being critical to this selection the limits imposed by the surge and choke lines [14]. At that point, different admission configurations should be studied so better results can be achieved.

In many modern engine configurations, due to the lack of space, it is becoming very common to have an elbow in the admission duct very close to the inducer of the centrifugal compressor [7]. This design solution, however, has important consequences on the surge limit and the compression ratio of the centrifugal compressor, possibly forcing the designer to choose different models for different elbow configurations if the compressor works near the surge line or the compression ratio or the maximum mass flow rate becomes lower than required.

To this extent, the main purpose of this work is to analyse the effect that $90^{\circ}$ elbows have on the compressor performance when installed close to the inducer and study different elbow configurations and geometries. All the elbows tested are designed to fit in the same space and are located at the same distance from the compressor inducer, but they differ in their external and internal geometry.

The different geometries proposed have been designed using a CFD code. Furthermore, they have been tested experimentally on a cold, continuous flow test rig. With the results of the experimental characterisation and the CFD modelling, a complete study of the effect of the elbows on the compressor behaviour has been conducted for some of the designed elbows.

Apart from this, an extra experiment has been conducted, which consists in generating a depression at the compressor inlet with a straight (no-elbow) configuration. The depression was generated with a restriction (automatic valve) placed close to the compressor, at the same distance where the elbow would be. The literature says that the compressor performance is not affected or it has no important implications [8], although it seems to produce an improvement in the surge limit area.

The paper is structured as follows. First, different elbow configurations are presented. Then, a CFD study is shown so a subset can be selected for building and testing. In the fourth section, a methodology to characterise the behaviour of elbows in a continuous flow test rig is exposed. In section 5, a testing campaign of a centrifugal compressor with inlet elbows in a specific test rig is presented. Next, the results are discussed. In the seventh section, the influence of low pressure at the compressor inlet is analysed. Finally, conclusions are exposed.

\section{Elbows Configuration}

The elbows have been developed considering different designs with the same main structure and occupying the same space. All the elbows had a circular outlet section of 
diameter $39.2 \mathrm{~mm}$, imposed by the inducer diameter of the compressor; and a rectangular entry section of $20 \times 60 \mathrm{~mm}$. The entry section shape was imposed by the strict limitations in space available in the studied car and it is representative of modern cars [7]. The space between the inducer and the engine was limited to $35 \mathrm{~mm}$ (Figure 1) so in order to have a reasonable radius at the elbow corner, it was decided that a rectangular entry section of the cited dimensions had to be used. The dimensions of the rectangular section were selected in order to match the area of the inducer as these would decrease the pressure drop produced by the change in section. Another imposed value in the design was that the elbows had to have a curvature of $90^{\circ}$.

The methodology used in the design was to compare the flow behaviour through the elbow and its evolution till the exit area, where the compressor inducer will be placed. The different geometries have been studied and parameters such as the flow uniformity and pressure loss indexes have been obtained from the CFD model. The different elbow configurations tested are further listed and represented schematically in Figure 1.

- V1: curvature radius $0 \mathrm{~mm}$.

- V2: Sharp elbow of curvature radius $5 \mathrm{~mm}$.

- V3: Smoother elbow with large inner elbow radius of $15.5 \mathrm{~mm}$.

- V4, V5, V6 and V7: Sharp V2 type elbows with internal directional plates of different shapes and locations.

- V8: Sharp V2 type elbow with internal wedge located before the elbow.

- V9: Smooth V3 type elbow with two flat internal plates at incidence

- V10: Similar to V3 type elbow but with the two internal curved guide vanes placed such that they divide the duct in three channels of the same crosssectional area

- V11: Smooth V3 type elbow with one internal curved guide vane placed such that it divides the duct in two channels of the same cross-sectional area.

\section{CFD evaluation}

The method used to find an optimum solution for the elbows has been carried out using a CFD commercial code. The FLUENT 6.0 program has been employed for all the calculations with the segregated implicit solver and the standard k- $\varepsilon$ turbulence model. The following assumptions have been made to reduce calculation time:

- The symmetry of the flow with respect to a mid-plane passing through the elbow axis allows reducing the number of cells, as only half the geometry needs to be calculated.

- The airflow is considered incompressible and therefore density is constant throughout the domain. The error made by this simplification is very low and does not affect the general conclusions of the comparative study performed here.

- Possible transitional and unsteady effects are also neglected. The convergence criteria used for the steady state calculations are based on small residuals (order 10e-4) and a stabilisation of the mass flow rate and the velocity profile at the duct exit. 
- A pressure difference between inlet and outlet of $1500 \mathrm{~Pa}$ has been imposed by the inflow/outflow pressure boundary conditions.

A structured mesh criterion was adopted with 26500 number of cells, value chosen after a mesh independence study. Four levels of mesh fineness were investigated, ranging from the coarsest one with 3300 cells to the finest with 150000 cells. The difference in the mass flow rate results between the finest and the chosen mesh was of $2 \%$, with a clear asymptotic behaviour for meshes finer than 26000 cells. In addition, to avoid boundary condition problems and obtain continuous flow at the outlet, a longer exit tube was used. The general mesh characteristics and boundary conditions can be observed in Figure 2.

Figure 3 shows the uniformity index and pressure loss coefficient for the same $\Delta p$ $(1500 \mathrm{~Pa})$ for all the elbows calculated, V1 to V11. Pressure loss coefficient $(\mathrm{K})$ is defined as shown in equation (1).

$$
K=\frac{\Delta p}{0.5 \rho u^{2}}
$$

Where:

$$
\begin{aligned}
& \rho=\text { density }\left(\mathrm{kg} / \mathrm{m}^{3}\right) \\
& u=\text { inlet flow velocity }(\mathrm{m} / \mathrm{s})
\end{aligned}
$$

The flow uniformity index $(\gamma)$ has been defined on the basis of the axial velocity at the entry section of the compressor. It takes the value 1 for the straight duct case [9].

$$
\xi=1-\sum_{i} \frac{\left|\left(W_{i}-W_{m}\right) a_{i}\right|}{2 W_{m} A}
$$

Where:

$\mathrm{W}_{\mathrm{i}}=$ axial velocity in cell $i$ of the compressor inlet

$\mathrm{W}_{\mathrm{m}}=$ axial average velocity at the compressor inlet section

$\mathrm{a}^{\mathrm{i}}=$ area of cell $i$.

$\mathrm{A}=$ area of the cross section

After analysing the results, the following four elbows were selected to be built and tested in the continuous flow and turbocharger test rigs due to the following characteristics:

- Elbow V1: curvature radius $0^{\circ}$. Used as reference of worst case.

- Elbow V3: lowest pressure drop coefficient

- Elbow V9: moderate pressure loss coefficient and high uniformity index

- Elbow V10: highest uniformity index

Figure 4 shows the CFD velocity pattern study for each of the four selected elbows. The circle magnified in each image represents the transversal inducer area. In the V1 case, it can be clearly seen that the flow is not well distributed in this section, while on 
the other three cases the flow distribution has been greatly improved. Elbow V1 was the most unstable, as proven by Figure 3 and Figure 4 in which it can be seen that it has the highest value of pressure loss of the selected elbows and the lower value of uniformity index. This elbow will be used as the base worst test case from which to make comparisons.

It has to be recalled that the objective of the CFD study was to compare different geometries. No further studies than the ones shown were carried out as the only purpose of this study was to evaluate and select the different geometries before they were built and tested.

\section{Continuous flow test rig}

To quantify the pressure loss coefficients of each elbow built, a continuous flow test rig is used. The methodology followed consists of two tests: A and B. Test A will be used to determine the pressure loss coefficient of the ducts and flanges that will be used to couple and fix the elbows to the rig in test B. Therefore using the results of both experiments, the pressure loss produced by the elbow can be established. Figure 5 shows a scheme of the experimental tests A and B. The pressure is measured in the settling tank and in the room using mean pressure transducers. The temperature is measured by means of $\mathrm{K}$ thermocouples.

The methodology used to calculate the pressure loss produced by the elbow is the following:

Every pressure loss coefficient $(K)$ referred to the ducts 1 and 2 is added resulting in a total $K$ of the test $\mathrm{A}$ as shown in equation 3:

$$
K_{A}=K_{1 i}+K_{d 1}+K_{d 2}+K_{d 2 e}
$$

where:

$$
K_{A}=\frac{\Delta p_{A}}{0.5 \rho_{i} u_{i}^{2}}
$$

and the density $\rho_{i}$ is calculated from ambient conditions at the inlet of duct $1 . K_{d l i}$ is the pressure loss coefficient of the connection with the atmosphere. $K_{d 1}$ is the pressure loss coefficient of duct $1 . K_{d 2}$ is the pressure loss coefficient of duct 2 . $K_{d 2 o}$ is the pressure loss coefficient of the connection between duct 2 and the settling tank.

Once the value of $K_{A}$ has been obtained, the test B is performed with the same elements of test A plus the $90^{\circ}$ elbow in order to obtain its pressure loss coefficient.

$$
K_{B}=K_{d l i}+K_{d 1}+K_{\text {elbow }}+K_{d 2}+K_{d 2 e}
$$

where:

$$
K_{B}=\frac{\Delta p_{B}}{0.5 \rho_{i} u_{i}^{2}}
$$


It is assumed that $K_{d l i}, K_{d 1}, K_{d 2}$ and $K_{d 2 o}$ are supposed to be the same as in test A.

Once $K_{B}$ is obtained from test $\mathrm{B}$, the subtraction of the two $K$ coefficients is performed and the $K$ value obtained corresponds to the tested element, in this case the $90^{\circ}$ elbow.

$$
K_{\text {elbow }}=K_{B}-K_{A}
$$

To calculate the pressure drop $\Delta p_{\text {elbow }}$ in the flow through the elbow, the obtained $K_{\text {elbow }}$ value is used as shows equation (8):

$$
\Delta p_{\text {elbow }}=K_{\text {elbow }} 0.5 \rho_{i B} u_{i B}^{2}
$$

The results extracted from these tests are shown in Figure 6, where the pressure drop and the loss coefficient $(\mathrm{K})$ are plotted versus the mass flow rate for every tested elbow (V1, V3, V9 and V10). Although the tests were carried out until a mass flow rate of $0.15 \mathrm{~kg} / \mathrm{s}$, the results over $0.1 \mathrm{~kg} / \mathrm{s}$ should not be considered as valid as they might have a significant error. This is because above this value, the velocity of the flow is above Mach 0.2, limit for which the hypothesis of incompressible flow used to calculate $\mathrm{K}_{\text {elbow }}$ and $\Delta \mathrm{p}_{\text {elbow }}$ ceases to be valid, as the density varies significantly. It is also interesting to note that the maximum possible mass flow achieved for elbow V10 was of $0.09 \mathrm{~kg} / \mathrm{s}$ due to flutter produced by the internal guide vanes.

Figure 6 shows the evolution of the discharge coefficient $C_{D}$ with respect to the air mass flow rate. The value of this coefficient, which refers to the loss of effective area produced by the elbow geometry, clearly drops beyond $0.1 \mathrm{~kg} / \mathrm{s}$. To calculate the $C_{D}$ coefficient the expression (9) has been used.

$$
C_{D}=\frac{\dot{m}_{\text {real }}}{\dot{m}_{\text {theoretical }}}
$$

Where the theoretic mass flow rate is calculated by Eq. 10

$$
\dot{m}_{\text {theoretical }}=A_{d} p_{a m b} \sqrt{\frac{2 \gamma}{R(\gamma-1) T_{a m b}}} \sqrt{\left(\frac{p_{s}}{p_{a m b}}\right)^{\frac{2}{\gamma}}-\left(\frac{p_{s}}{p_{a m b}}\right)^{\frac{\gamma+1}{\gamma}}}
$$

From these experiments the general conclusion is that the maximum pressure drop has been observed in elbows V1 and V9, just as was predicted with the CFD tests. On the other hand, the elbow that produces the lowest pressure drop is V3. Very similar results have been observed when analysing the discharge coefficient $\left(C_{D}\right)$, with the highest value observed for elbow V3 and the lowest for elbow V9. It is interesting to highlight that the $C_{D}$ value for $V 1$ is below 0.65 , implying that only $65 \%$ of the geometric area is used by the flow.

The measured data have been compared with the CFD calculations performed for the different elbows, as shown in Figure 7. Clearly, the trend observed in the 
experimental work for the pressure loss coefficient $\mathrm{K}$ of each geometry is well predicted by the CFD results, although the numerical values are under-predicted. This may be explained as follows: first, the pressure drop imposed between inlet and outlet of the CFD geometry does not take into account the pressure losses termed $\mathrm{K}_{\mathrm{d} 1 \mathrm{i}}$ at the inlet, $\mathrm{K}_{\mathrm{d} 1}$ of the inlet duct and $\mathrm{K}_{\mathrm{d} 2 \mathrm{o}}$ at the settling tank entry; since these are constants for a particular mass flow rate, they entail a systematic constant difference with the experimental data. Furthermore, the junctures between the inlet and outlet ducts and the elbow are considered smooth and continuous in the CFD calculation, while for the experiments, these were not and therefore caused further pressure losses. In this case, each elbow required a different connection, so that the corresponding pressure losses varied from one geometry to the other. Hence, the CFD pressure loss is significantly less and the difference with the experimental values is not constant.

However, since the trend is the same, it may be concluded from these studies that the pressure drop coefficient is maximum in the case of the V1 and V9 configurations (as was also predicted by the CFD calculations) and minimum in the case of $\mathrm{V} 3\left(90^{\circ}\right.$ elbow with large inner radius and without blades). Indeed, the value of the $\mathrm{V} 3 \mathrm{~K}$ coefficient is about $1 / 4$ of that of the V1 and 1/3 of that of the V9. The V10 case shows also a fairly low pressure drop coefficient, but still almost twice as high as that of the V3 elbow.

\section{Compressor and elbow tests in a specific rig}

The experimental tests with the centrifugal compressor and the elbows were carried out in the continuous, hot flow turbocharger test bench, where the compressor can be characterised and its map can be obtained [10]. In this experimental facility, the surge line is determined analysing the instantaneous pressure recorded upstream and downstream of the compressor. This is done by a sequential analysis of all the measured points applying FFT [10]. The compressor is characterised by recording the values of rotor speed, pressure ratio, air mass flow and temperatures. Compressor efficiency and total to total compression ratio are calculated.

Figure 8 shows a diagram of the turbocharger test bench installation with the instrumentation used and its location. The number and position of the pressure and temperature transducers satisfy the SAE standards [11]. The main instrumentation used in these tests is the following:

- Compressor air mass flow rate: Hot-film anemometers (range: $0-720 \mathrm{~kg} / \mathrm{h}$ with an expanded uncertainty of less than $1 \%$ of the measured value for mass flow rates bigger than $18 \mathrm{~kg} / \mathrm{h}$ )

- Inlet and output compressor instantaneous pressures: Piezo-resistive transducers (range: $0-5$ bar)

- Inlet and output compressor temperatures: Thermocouples type K (range : 20 $1300{ }^{\circ} \mathrm{C}$ with an expanded uncertainty of $1.5^{\circ} \mathrm{C}$ )

- Turbocharger speed: Eddy current sensor (range: $0-400 \mathrm{~K} \mathrm{~min}^{-1}$ )

An initial test with a straight pipe line at the compressor inlet was carried out in order to obtain the compressor map which will be used as a base for comparison. The same test was repeated for each of the selected elbows, as these permitted comparisons between the compressor maps with and without the $90^{\circ}$ elbows. 
Figure 9 shows the results of these experiments: all tested elbows are not just compared with the original straight duct, but also with the V1 elbow, since this was considered as the worse reference elbow design, with the lowest uniformity index and the highest pressure drop. This permitted not only to assess the different effect between an elbow and a straight configuration, but also between a badly designed elbow and a more sophisticated design.

The effects of installing the V1 elbow can be easily spotted when comparing with the original compressor configuration (see Figure 9). The surge limit seems to be unaffected for compression ratios over 2, but below this value, the surge limit shifts to the right in the presence of the V1 elbow, meaning that the compressor will surge at higher mass flow rates. This is obviously a negative effect, as it reduces the mass flow range. But apart from this, the V1 elbow also has very negative effects on the pressure ratio and on the maximum flow rate: for the same rotor speed, the compression ratio is always lower. This can be clearly seen at the highest velocities where the difference is greater. Furthermore, the maximum flow rate has also been reduced significantly when using this elbow, making the admissible operating flow range even smaller.

On the other hand, by observing Figure 9c it can be seen that the V10 elbow configuration manages to shift the surge limit to the left, implying that the compressor will surge at lower mass flows, which is always a benefit. Unfortunately, just as with elbow V1, the compression ratios achieved are smaller than with the original configuration. This time though, the effect is slightly different as the drop in compression ratio does not come with the increase in rotor speed but with the increase in mass flow rate. For a given speed and low mass flow rates, the values of compression ratio are similar to the original results, but as the mass flow rate increases, the compression ratio falls and results become very similar to those with elbow V1. Also, just like with V1, the maximum mass flow rate allowed is reduced, but this time, as the surge line is shifted to the left, the admissible operating flow range does not vary significantly.

The results obtained when testing elbow V3 can be seen in Figure 9a. Once again, the surge limit has been shifted to the left, benefiting the compressor behaviour at low mass flow rates, but as seems common with the elbow configuration, the compression ratio also drops. This time though, it shows an opposite trend to elbow V10. For a given rotor speed and low mass flow rate, the compression ratio is the same as with elbow V1, but as the mass flow rate increases, the compression ratio increases significantly close to values observed with the original no-elbow configuration. This is because the lowest pressure drop coefficient was measured with V3 elbow.

Figure 9b shows the effect that elbow V9 has on the compressor map. Again, the surge limit has been shifted to the left, but the compression ratios have dropped significantly showing very similar results to those obtained with the V1 elbow, as expected considering Figure $6 \mathrm{~b}$ results.

The reason why these effects are happening will be further discussed. In Figure 9d the results of all the elbows are combined and only the region of high compression ratio and low mass flow rate is shown for readability. This figure will help to better understand further discussion. 


\section{Discussion of results}

In order to understand why the surge limits change, it is fundamental to understand why surge happens. In the impeller of a compressor, the airflow pressure is higher downstream than upstream, therefore creating a pressure gradient opposite to the streamline direction. As the mass flow rate decreases, for a constant rotor velocity, the adverse pressure gradient increases, which at the same time increments the viscous shear stress at the impeller blades. At a certain point of the impeller wall, the flow velocity becomes zero because the momentum in the streamline adjacent to the wall is insufficient to overcome the adverse pressure gradient and viscous stress. Unfortunately this situation deflects the streamlines and affects directly the boundary layer, which increases its thickness. This situation will create reverse flow that will increase in the surface of impeller wall as the compressor gets closer to the surge point. When the reverse flow becomes more important than the main flow, the rotor compressor velocity is insufficient to overcome the magnitude of the adverse pressure gradient, therefore the streamlines completely deflect from the impeller wall, creating an abrupt stall for all the rotor impellers and consequently generating surge.

Among the parameters evaluated in this study, the uniformity index of the flow in the elbows has the highest impact on the surge limit. Figure 9d shows the elbows with the highest uniformity index (V3, V9 and V10) and a benefit in the surge limit can be observed. On the other hand, the V1 elbow that has a uniformity index of 0.742 does not show this behaviour. As is shown in Figure 4, the CFD analysis shows that in an important part of the area at the inducer inlet the flow is separated and its velocity is close to zero for elbow V1. This has a very negative impact on the uniformity of the flow, making it very irregular at the impeller's surface, resulting in distortions that will cause rotating stall and surge.

Discharge coefficient $\left(\mathrm{C}_{\mathrm{D}}\right)$ is another important parameter that affects the surge limit. As for all the cases this value is below 1 and the mass flow has not been changed, according to the continuity equation, this implies that the velocity of the flow at the inducer is higher. It has to be recalled that surge occurs when the reverse flow, produced by the adverse pressure gradient, is more important than the main flow; therefore, increasing the velocity of the main flow at the compressor inlet will delay surge and make the compressor more stable. This effect, combined with a more uniform flow, benefits the compressor behaviour at low mass flows and moves the surge limit to the left of the map.

It is important to note that although the $C_{D}$ of elbow V1 is very low, which should be theoretically beneficial in shifting the surge limit to the left, its uniformity index is very low with high asymmetric flow cancelling all the other possible benefits. On the other hand elbow V3 and V10, show a $C_{D}$ closer to 1 , which is not so beneficial for surge, but this is compensated by having a very high uniformity index. V3 elbow shows the best characteristics (Figure 9d) at high compression ratios.

With respect to the drop in compression ratio when compared to the original noelbow case, the explanation is pretty simple: it is due to the pressure loss produced by the different elbow configurations. Although the compressor is compressing at the same ratio, the fact that the inlet pressure at the inducer is lower (due to the elbows pressure loss), implies that the pressure at the outlet will also be lower. As it can be seen in 
Figure 8, the inlet pressure sensor is not installed at the inducer, but at the inlet of the elbow, so when calculating the compression ratio, the pressure loss produced by the elbow is included in the calculation.

In order to deduct the effect of the pressure loss produced by the elbow and observe the real compression ratio, the pressure loss calculated in the continuous flow test rig for all the elbows has been subtracted from the elbow inlet pressure, so as to obtain the pressure at the inducer. This is shown in equation 11, where $\Delta p$ is the pressure loss of every elbow which varies with the mass flow rate.

$$
\pi_{\text {with elbow }}=\frac{p_{\text {outlet }}}{p_{\text {elbow inlet }}}<\pi_{\text {without elbow }}=\frac{p_{\text {outlet }}}{p_{\text {elbow inlet }}-\Delta p_{\text {elbow }}}
$$

The new results are plotted in Figure 10, where it can be seen that with this correction, there is hardly any difference in compression ratio, except at the maximum tested rotor speed. In this case, it can be observed how the elbows with higher uniformity index (V9 and V10) have the same compression ratio as the original test case with no elbow; while on the other hand, the elbows with a lower uniformity index show reduced compression ratios at high rotor speeds.

Figure 11 shows the plot of the compressor efficiency with respect to mass flow rate for three different rotor speeds, comparing also the effect of adding or subtracting the pressure loss produced by the different elbow configurations. As can be seen, when the pressure loss is subtracted, the compressor efficiency seems almost unaffected. The best results are obtained with the elbows V3 and V10, which have the lowest pressure drop coefficient. However, if $\Delta p$ is included in the calculations, as the mass flow increases, the efficiency reduces with respect to the original no-elbow case.

This can be explained using an enthalpy-entropy diagram as shown in Figure 12 . With a straight duct fitted on the compressor, the inlet pressure would be atmospheric pressure $\left(\mathrm{p}_{\text {atm }}\right)$, while its exit pressure would be $\mathrm{p}_{2}$ '. On the other hand, if an elbow is installed at the compressor inlet and the pressure still measured from the compressor inducer $\left(\mathrm{p}_{1}\right)$ to the compressor exit $\left(\mathrm{p}_{2}\right)$, the compression ratio would still be the same as before, but both inlet and outlet pressures would be lower, due to the pressure drop produced by the elbow at the compressor inlet. Conversely, if the pressure is measured from the elbow inlet $\left(\mathrm{p}_{\mathrm{atm}}\right)$ to the compressor exit $\left(\mathrm{p}_{2}\right)$, the compression ratio is reduced as it includes the loss in pressure produced by the elbow. This is the reason why the efficiency is lower when taking into account the complete system (elbow + compressor). Reducing the compression ratio for the same energy determines a decrease in the efficiency of the compressor. Thus, to achieve the same compressor outlet pressure as in the case without elbow, it is necessary to give more power to the compressor itself. The elbow produces a pressure loss which affects the efficiency of the compressor. If this loss is subtracted, as seen in Figure 11, there is virtually no difference in efficiency.

$$
\eta_{p_{a t m}-p_{2}^{\prime}}=\eta_{p_{1}-p_{2}}>\eta_{p_{a t m}-p_{2}}
$$

\section{Influence of the lower pressure at the compressor inlet.}


A second series of tests were carried out in order to experimentally confirm that the main parameters that affect the surge limit on a radial compressor are uniformity index and flow velocity. Flow velocity was achieved by reducing $C_{D}$ as discussed in previous sections.

These tests were carried out using a straight, no-elbow duct with a valve upstream in order to generate a pressure drop. The main function of this valve is to create an increase in speed and a reduction in pressure at the compressor inducer, while the mass flow is kept constant. These can be explained by means of the continuity equation, as if the mass flow is kept constant and the flow density is reduced (higher pressure drop), this will produce an increase in flow speed. Two different pressure drops were measured: $150 \mathrm{mbar}$ and $300 \mathrm{mbar}$. The valve was also positioned 14 diameters upstream of the mass flow measuring plane placed 10 diameters before the inducer. These distances were selected in order to obtain a good uniformity in the flow. A sketch of the installation can be seen in Figure 13.

As can be observed in the results shown in Figure 14 the influence of the depression at the compressor inducer has almost negligible effects on the compression ratio. This was the expected behaviour attending to the results obtained, where the pressure drop was discounted in the $90^{\circ}$ elbows tests. The variables represented in these figures have been always corrected with the flow conditions just upstream the compressor.

The surge line has been shifted to the left in both cases confirming that flow velocity at the inducer and flow uniformity are the main parameters affecting surge. Unfortunately, the compressor choke line has also shifted to the left, reducing the maximum mass flow rate in the compressor. So this set up is just for phenomena demonstration, because although it shows very positive results with respect to the surge line limit, all this benefits are lost with respect to the choke line limit, as the mass flow operating range of the compressor has been reduced.

\section{Conclusions}

The authors have found two phenomena having a major effect on the compressor performance when an elbow with a $90^{\circ}$ corner is installed at the compressor inducer:

- The flow uniformity index.

- The pressure drop coefficient.

Both effects appear interdependent and affect mainly the surge limit of the compressor and the compression ratio:

- The higher the uniformity index the better, as there will be no irregularities in the flow at the impeller surface.

- On the other hand, a high pressure drop means low discharge coefficient, implying high flow velocity at the inlet and delaying surge, but it has the negative effect of reducing the compression ratio, due to the pressure loss produced at the compressor inlet. Also, although a low discharge coefficient is beneficial for surge, it is disadvantageous for choke. As shown, although 
the surge line shifts to the left, the choke does the same, so the maximum flow allowed by the compressor is reduced.

- Therefore, it is important to design elbows with the maximum uniformity index possible, as this has no drawbacks; in addition, the design should have the lowest possible pressure drop. Indeed, although a high pressure drop is beneficial for surge, it has other major downsides, so it is preferable to keep it as low as possible.

Considering the results presented in this article and its conclusions, elbow V10 can be confirmed as the optimum solution of all the elbows tested, since it has the highest uniformity index and a low discharge coefficient. Nevertheless, elbow V11 could be even better due to a small difference in uniformity index $(\xi)$ and sensibly lower pressure drop. Of course, both elbows are optimums if the modification of the surge limit is critical. If surge limit is not an issue, V3 is the best elbow because its pressure loss is the lowest from all the elbows studied.

Obviously, choosing the right elbow configuration in a very space-constrained case such as the one studied in this paper depends upon the relative importance of the surge limit and the allowable pressure loss:

- With elbows of high curvature radius lower pressure drops can be achieved, so this parameter should be kept as high as possible.

- If the surge limit is very restrictive, large vanes should be used to rise the uniformity index and move to the left the surge limit, but one should use as few vanes as possible because they also cause higher pressure losses.

References

1. White, F.M., "Fluid Mechanics", McGraw-Hill, Inc., 2003, ISBN-0-07-2402172.

2. Moore, F.K., "A Theory of Post-Stall Transient in Multistage Axial Compressor Systems", NASA, cr 3878, March 1985.

3. Siedel, U., Chen, J., Haupt, U., Hasemann, H., Jin, D., Rautenberg, "Rotating Stall Flow and Dangerous Blade Excitation of Centrifugal Compressor Impeller, Part 1 Phenomenon of Large -Number Stall Cells", ASME 1991, Paper No. 91GT-102.

4. Soranna, F., Chow, Y.C., Uzol, O., Katz, J., "The Effect on Inlet Guide Vanes Wake Impingement on the Flow Structure and Turbulence around a Rotor Blade", ASME Journal of Turbomachinery 2006, Vol.128, pp.82-95.

5. Engada, A., Kim, Y., Aungier, R., Direnzi, G., "The Inlet Flow Structure of Centrifugal Compressor Stage and Its Influence on the Compressor Performance", ASME, Journal of Fluid Engineering, September 2003, Vol. 125, pp. 779-785.

6. Elder, R.L., Gill, M.E., "A Discussion of the Factors Affecting Surge in Centrifugal Compressors", ASME, Journal of Engineering for Gas Turbines and Power, April 1985, Vol. 107, pp. 499-506.

7. J.Galindo, J.R.Serrano, X.Margot, A.Tiseira, N.Schorn, H.Kindl. "Potential of flow pre-whirl at the compressor inlet of automotive engine turbochargers to 
enlarge surge margin and overcome packaging limitations". International Journal of Heat and Fluid Flow 28 (2007), pp. 374-387.

8. Pampreen, R.C., "Compressor Surge and Stall", 1993, Concepts ETI, Inc ISBN 0-933283-05-9.

9. Kindl, H., Schorn, N., Schulte, H., Serrano, J.R., Margot, X., Donayre J.C., "Influence of Various Compressor Inlet Designs on Compressor Performance", September 2004, Valencia, Spain. THIESEL 2004, pp. 103-115.

10. J.Galindo, J.R.Serrano, C.Guardiola, C.Cervelló. "Surge limit definition in a specific test bench for the characterization of automotive turbochargers". Experimental Thermal and Fluid Science 30 (2006), pp. 449-462.

11. Supercharger Testing Standard, 1995. SAE J1723 ISSUED Aug95. 909 Society of Automotive Engineers, Inc.

12. M.Canova, "Development and validation of a control-oriented library for the simulation of automotive engines", International Journal of Engine Research 2004 5:219.

13. N. P. Kyrtatos, E. I. Tzanos and C. I. Papadopoulos, "Diesel engine control optimization for transient operation with lean/rich switches", International Journal of Engine Research 2003 4: 219.

14. E Mattarelli, "Virtual design of a novel two-stroke high-speed direct-injection diesel engine", International Journal of Engine Research 2009 10: 175. 


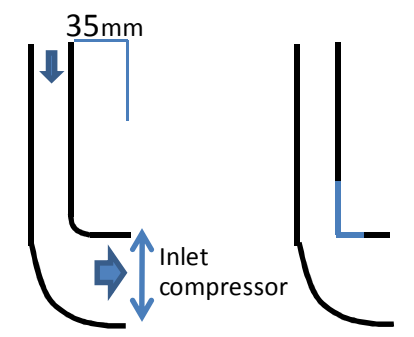

Flow direction

$\mathrm{V}-1(\mathrm{r}=0 \mathrm{~mm})$

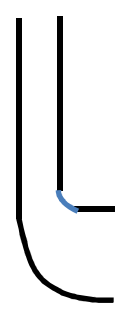

$V-2(r=5 \mathrm{~mm})$

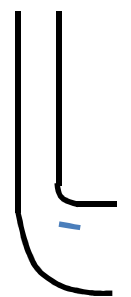

V-6 $(r=5 \mathrm{~mm})$ 1 small vane

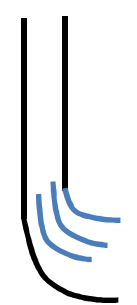

V-10 $(r=15.5 \mathrm{~mm})$ 2 large vanes

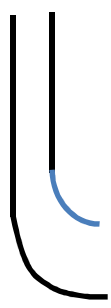

$V-3(r=15,5 \mathrm{~mm})$

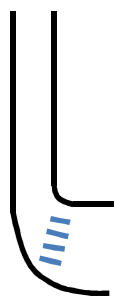

$\mathrm{V}-7(\mathrm{r}=5 \mathrm{~mm})$ 4 small vane

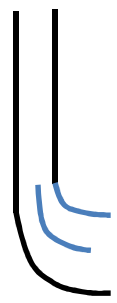

V-11 $(r=15.5 \mathrm{~mm})$ 1 large vanes

Figure 1. Variant of elbows propose 


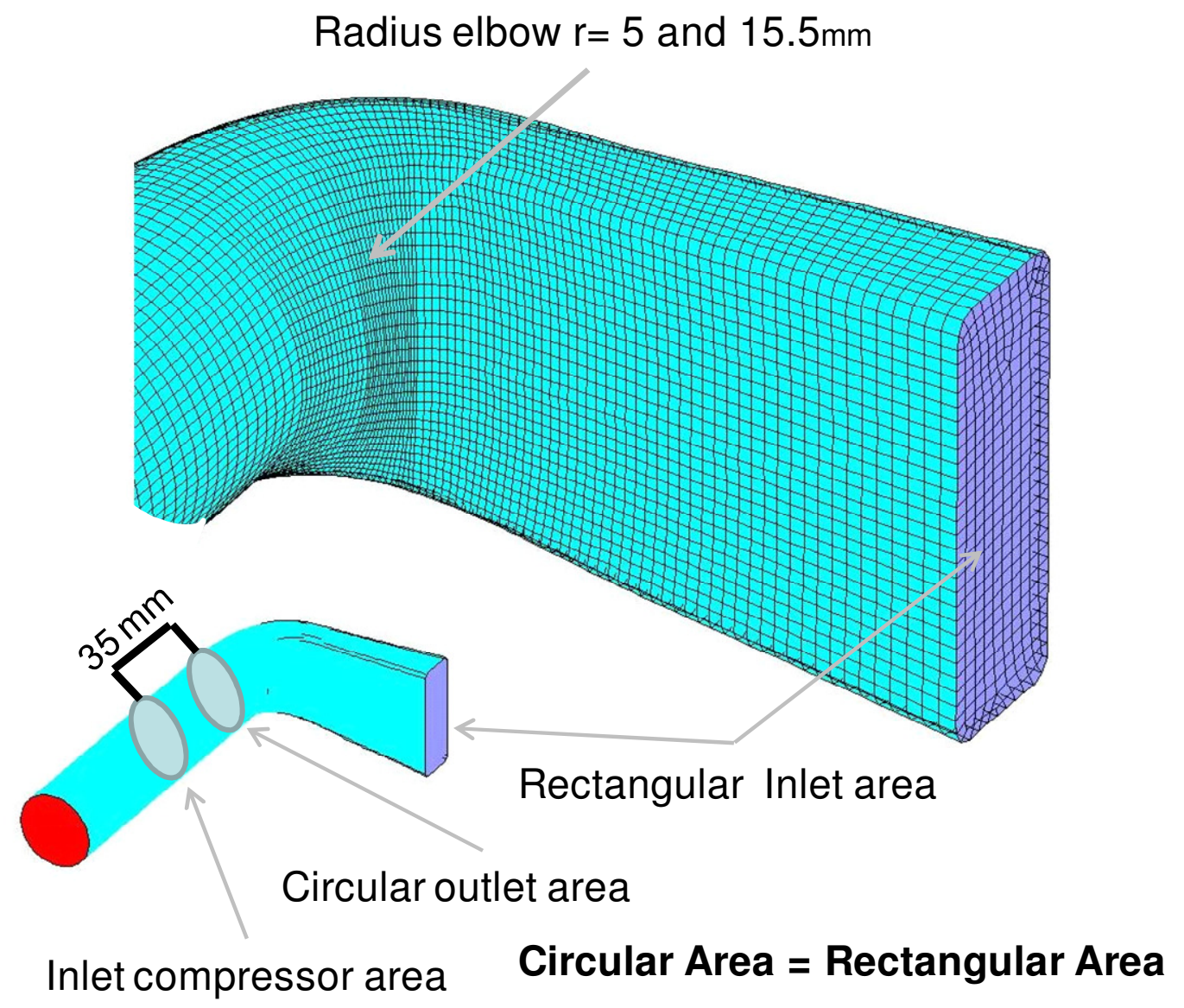

Figure 2. Characteristic mesh used to calculate the flow behaviour inside the elbows 


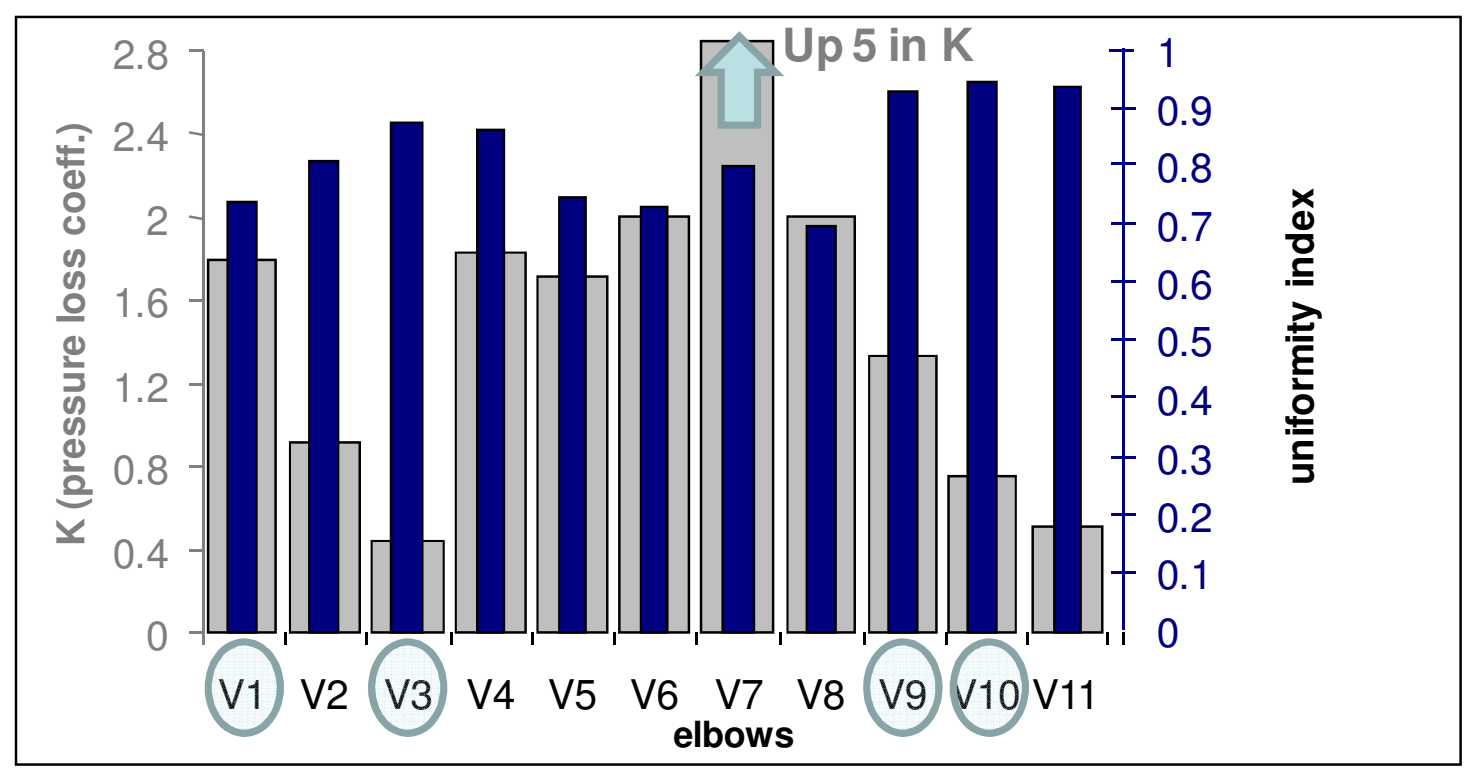

Figure 3. Graphic corresponding to uniformity index and pressure loss for each elbow at $0.1 \mathrm{~kg} / \mathrm{s}$ 

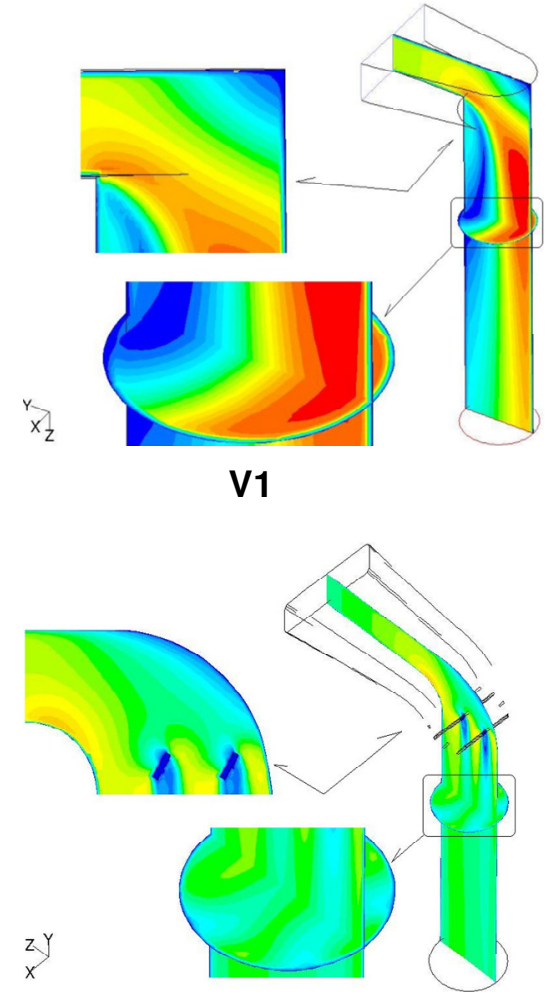

V9

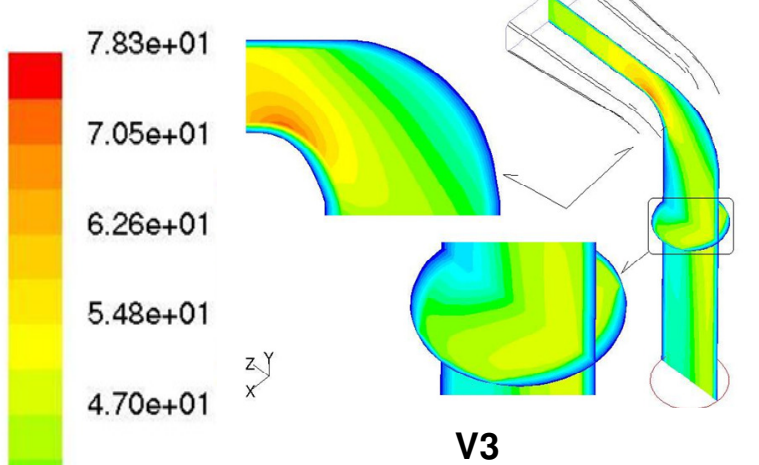

$3.92 e+01$

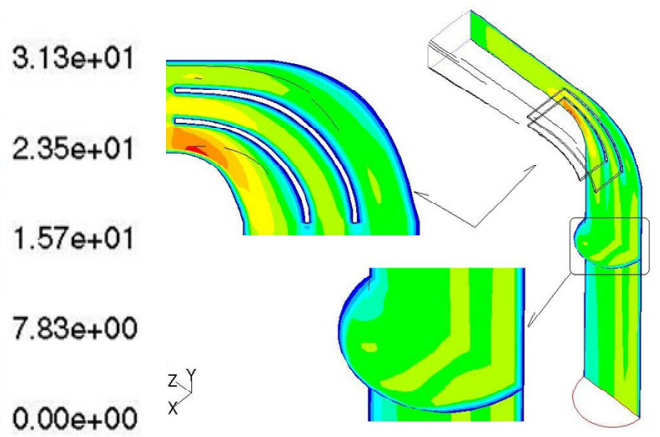

V10

Figure 4. Pattern flow described by the calculus CFD (the circle shows the inducer area), the V1, V3, V9 and V10 are the elbows built. 

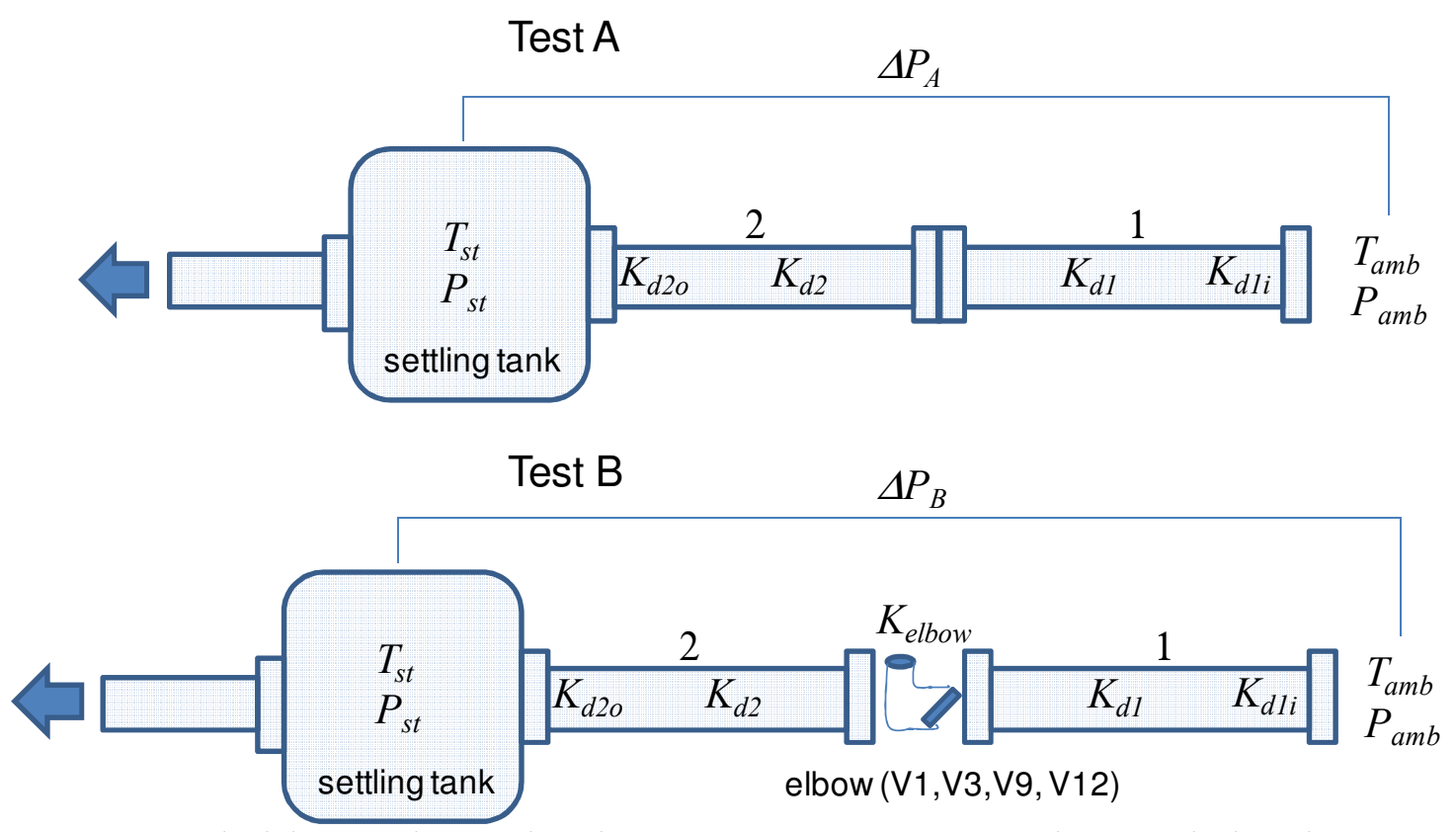

Figure 5. Methodology implemented in the test rig using two tests $A$ and $B$, to calculate the pressure drop caused by the elbows built. 
(a)
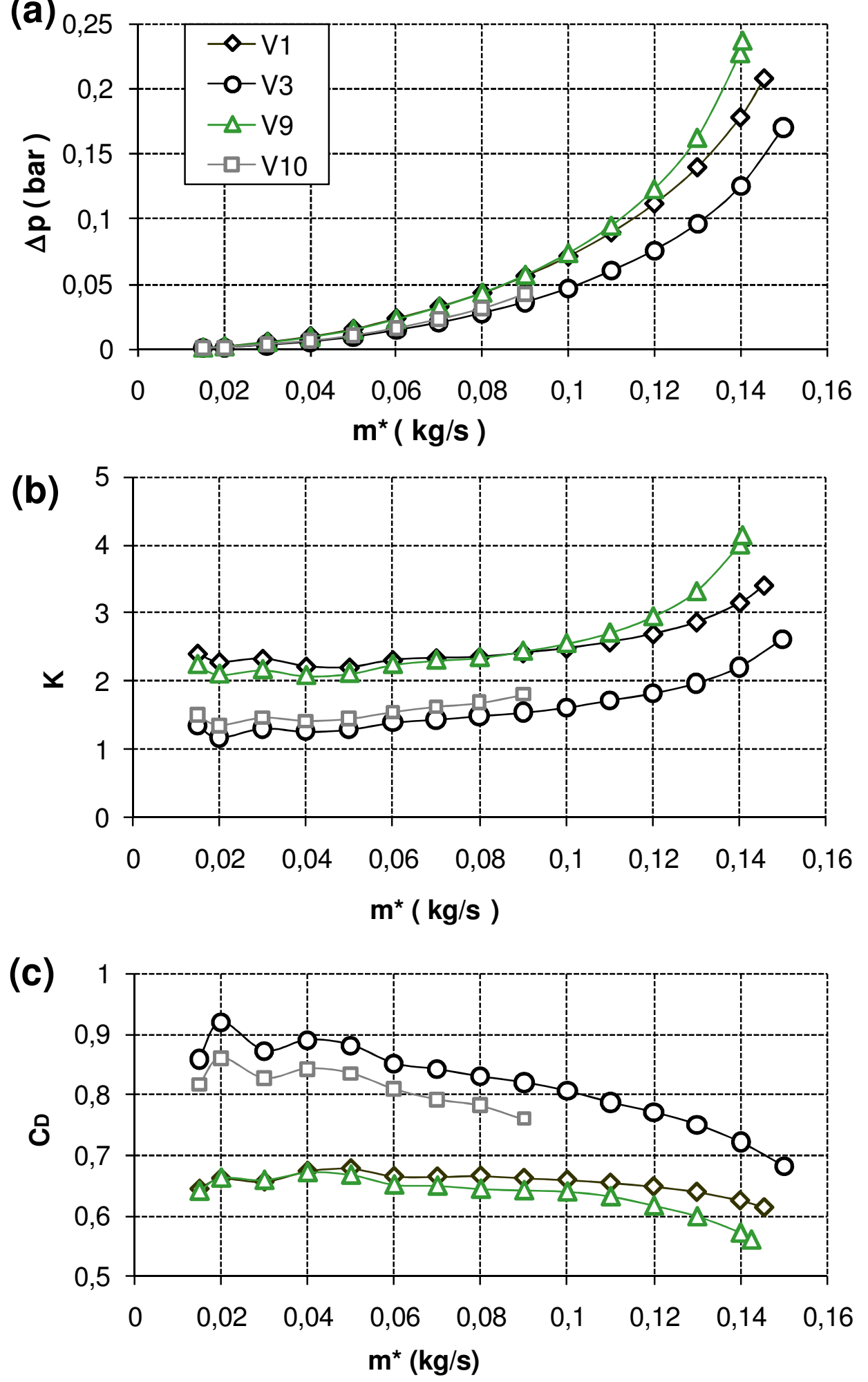

Figure 6. Variation of pressure loss, pressure loss coefficient (K) and discharge coefficient (CD) with respect to mass flow for all the tested elbows. 


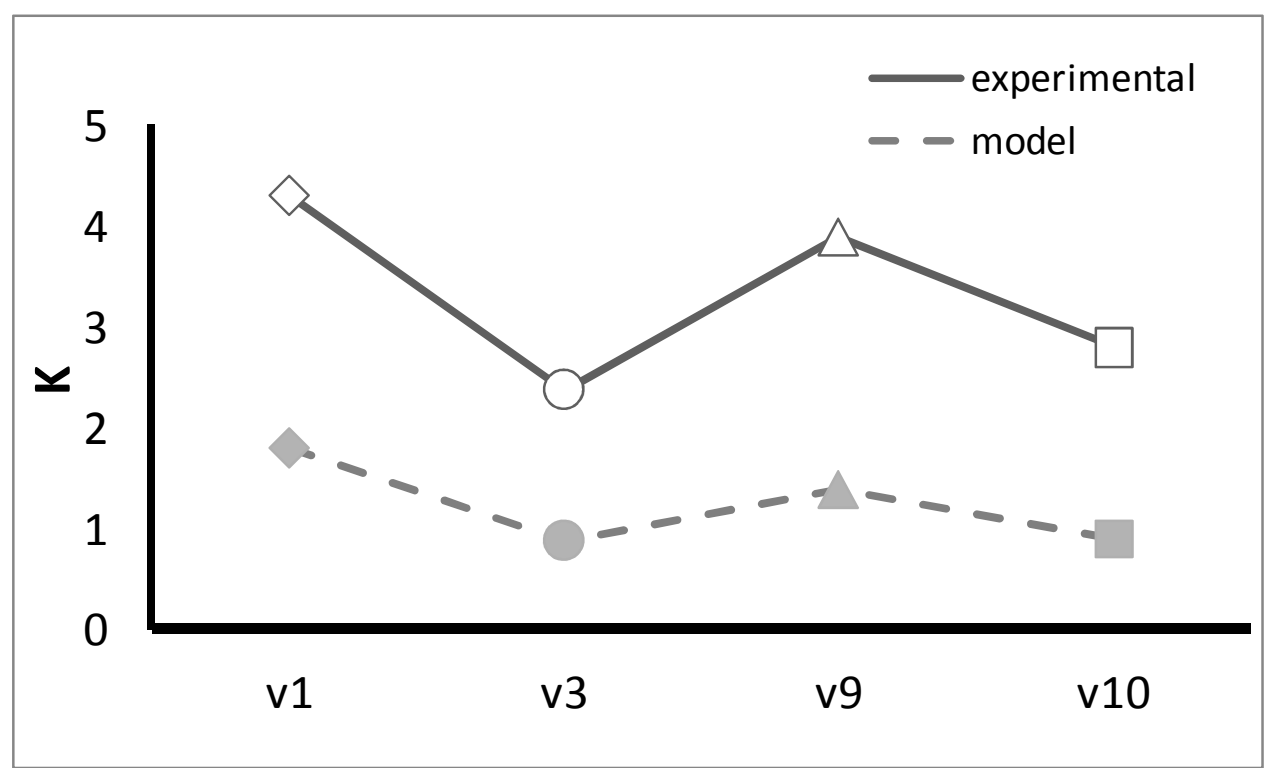

Figure 7 Comparison between experimental and model results. 


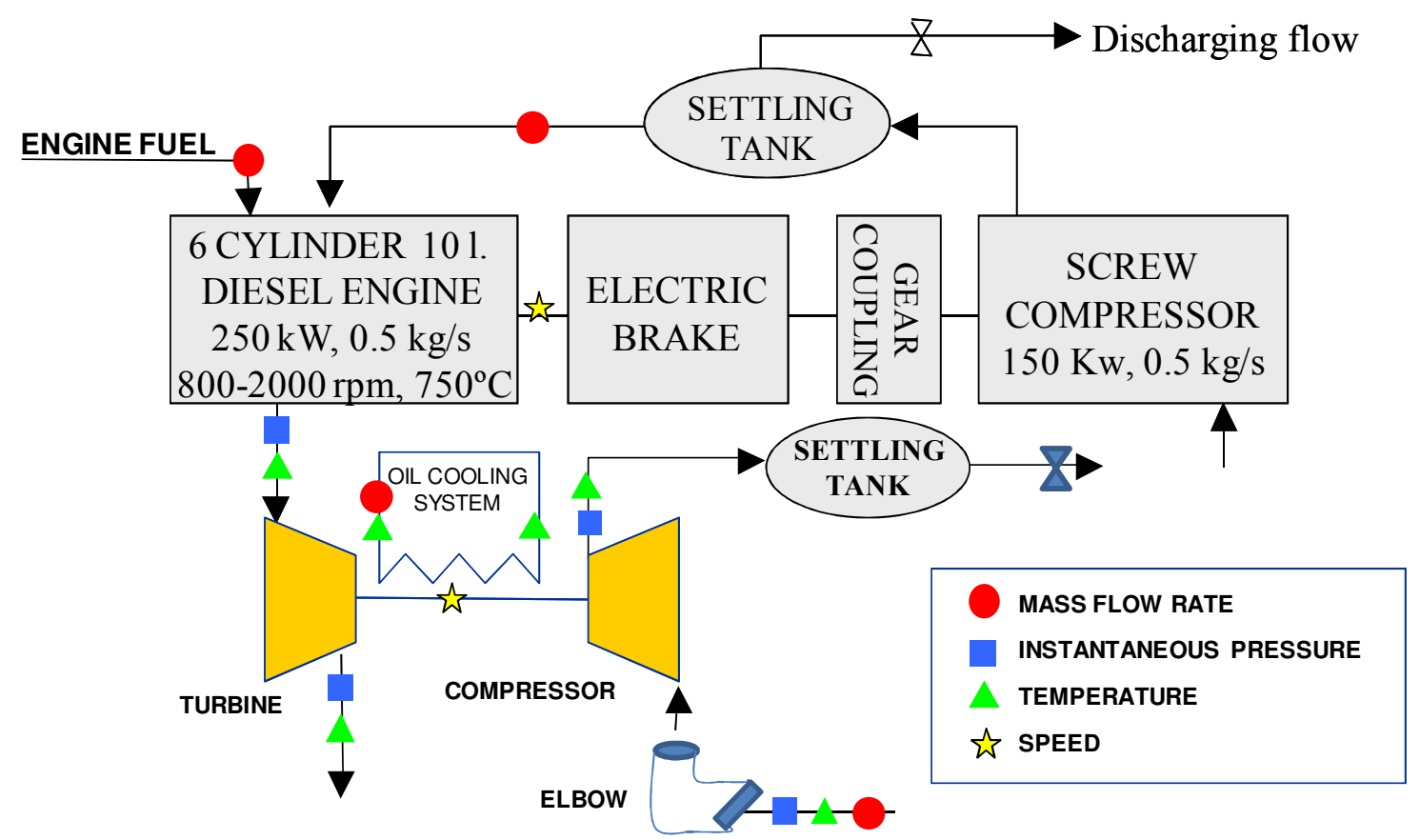

Figure 8. Turbocharger test bench installation and instrumentation 

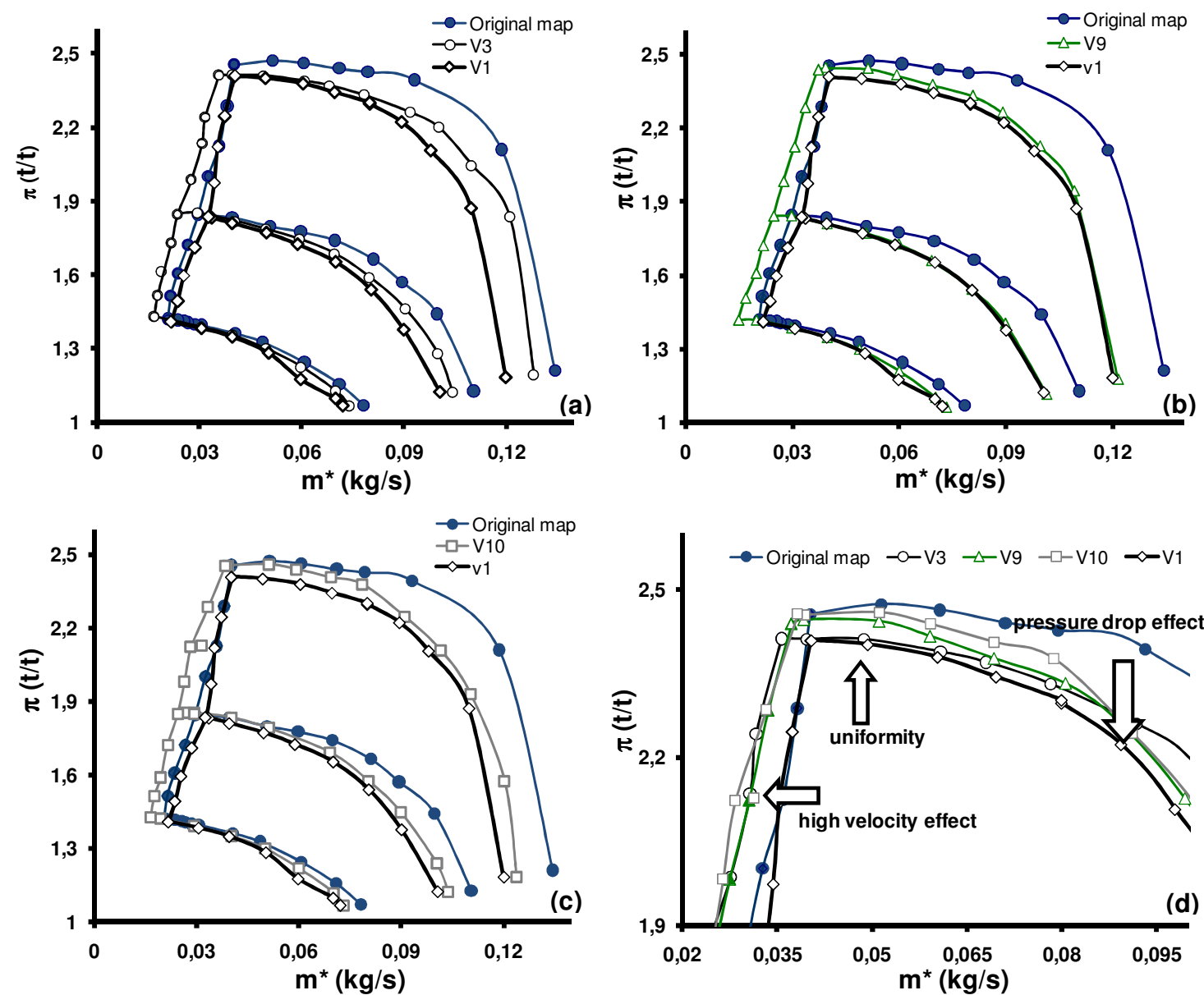

Figure 9. The maps compressor obtained in the turbocharger test bench (V1,V3, V9, V10 and original straight admission) 

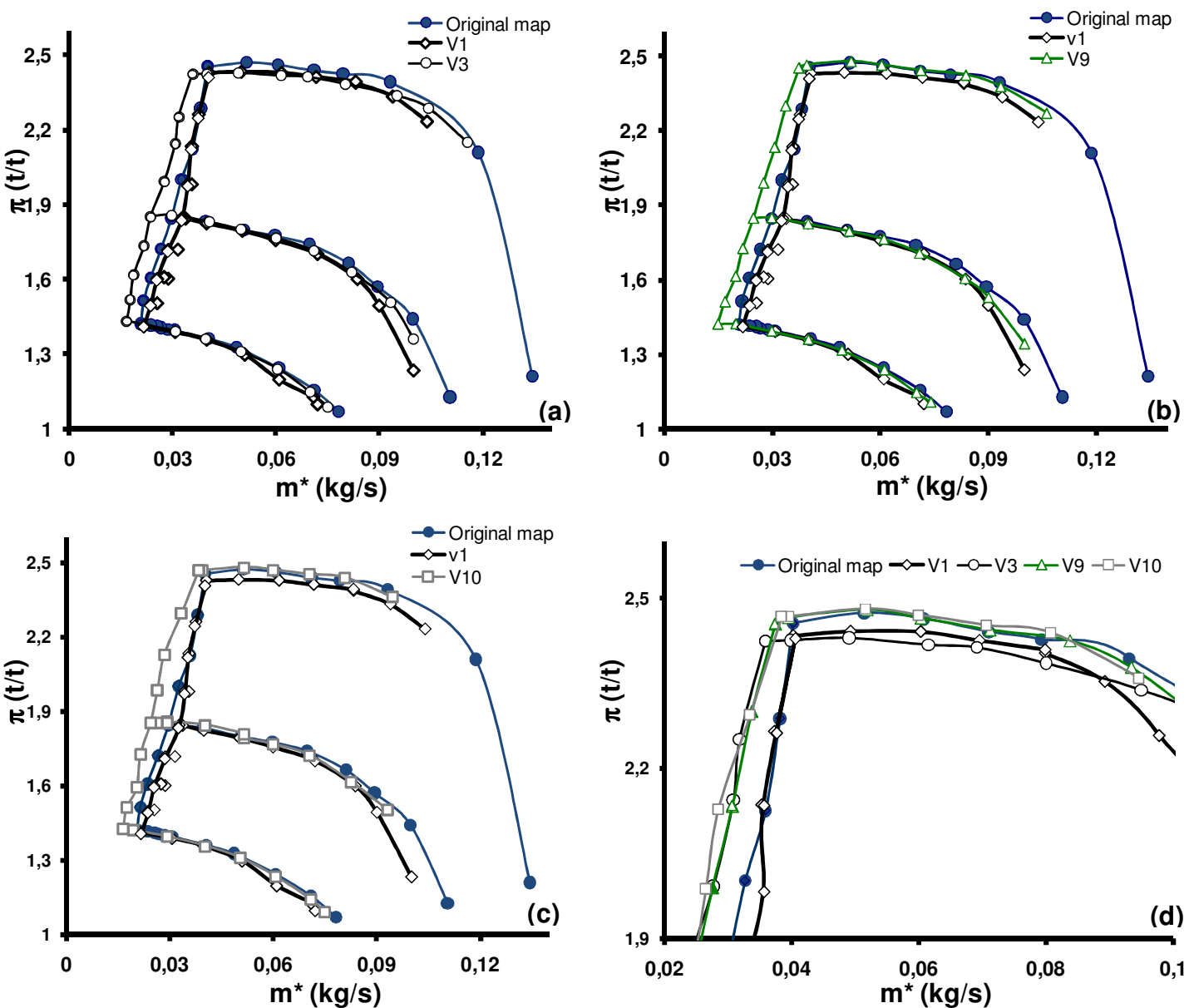

Figure 10. Each case of elbows map with pressure loss added through the results obtained in the test rig. 

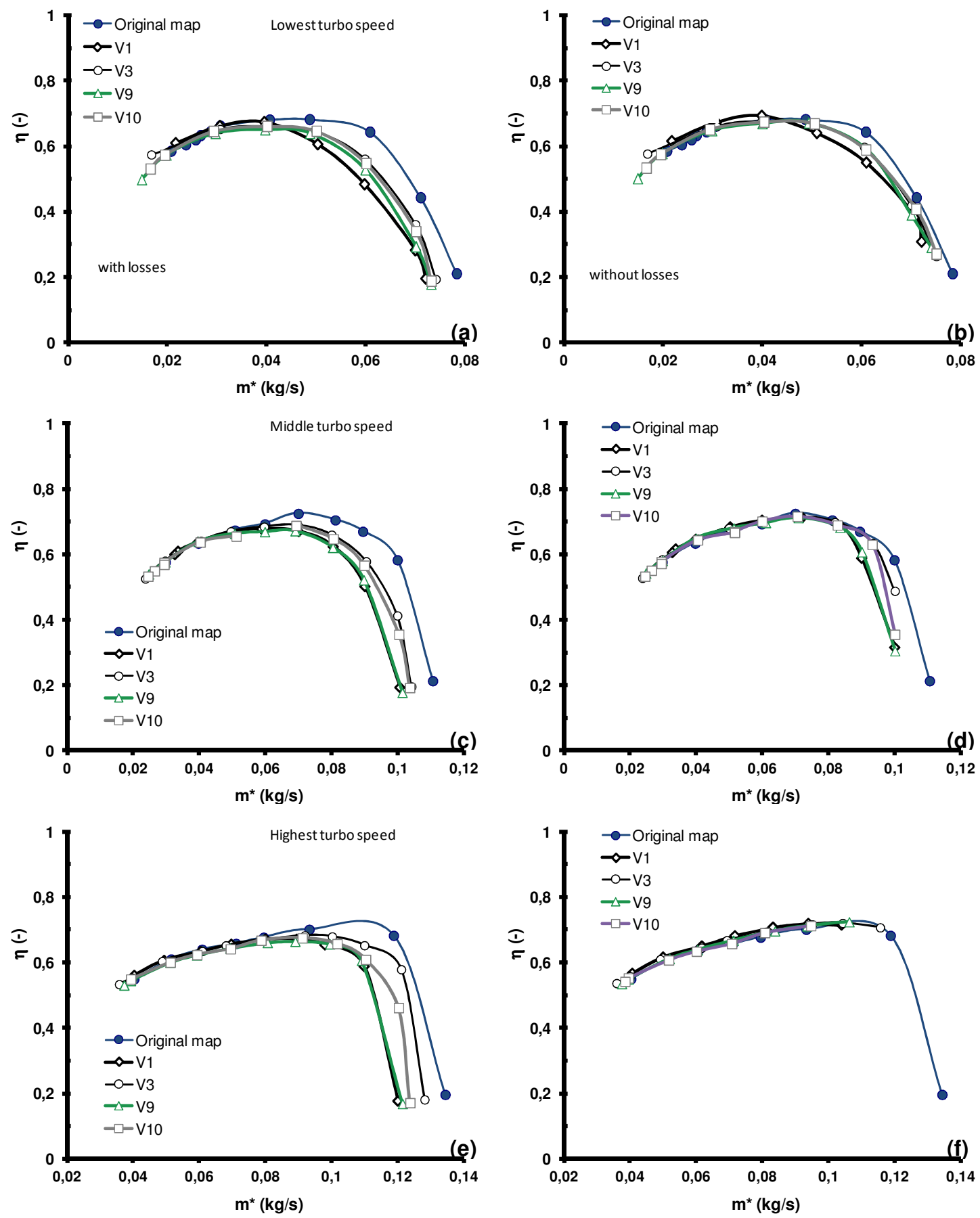

Figure 11. Efficiency comparisons among the different situation with and without pressure loss 

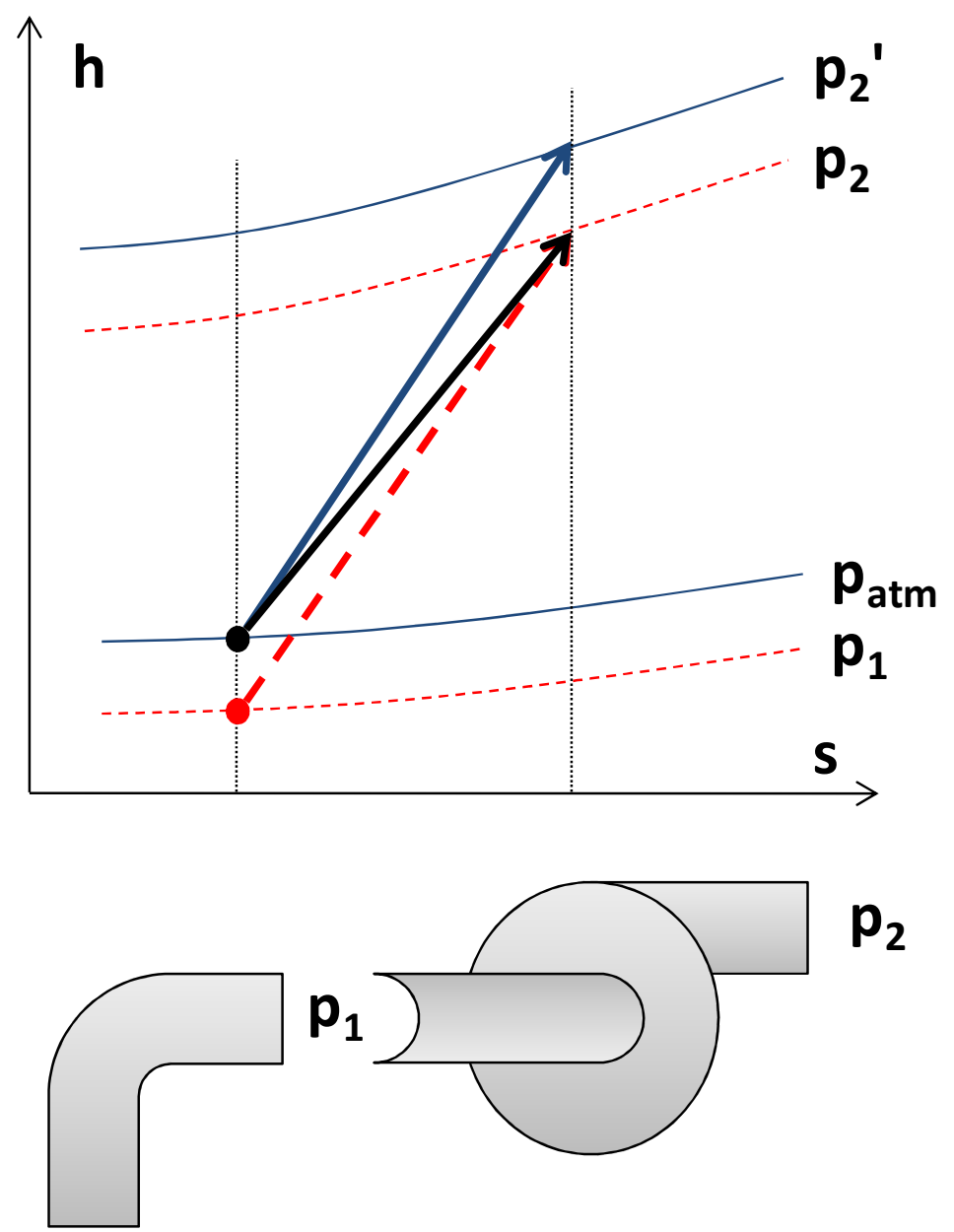

$p_{2}$

$p_{\text {atm }}$

Figure 12. Compressor enthalpy-entropy diagram showing the effect of the pressure loss produced by the elbow at the compressor inlet on the compression ratio. 


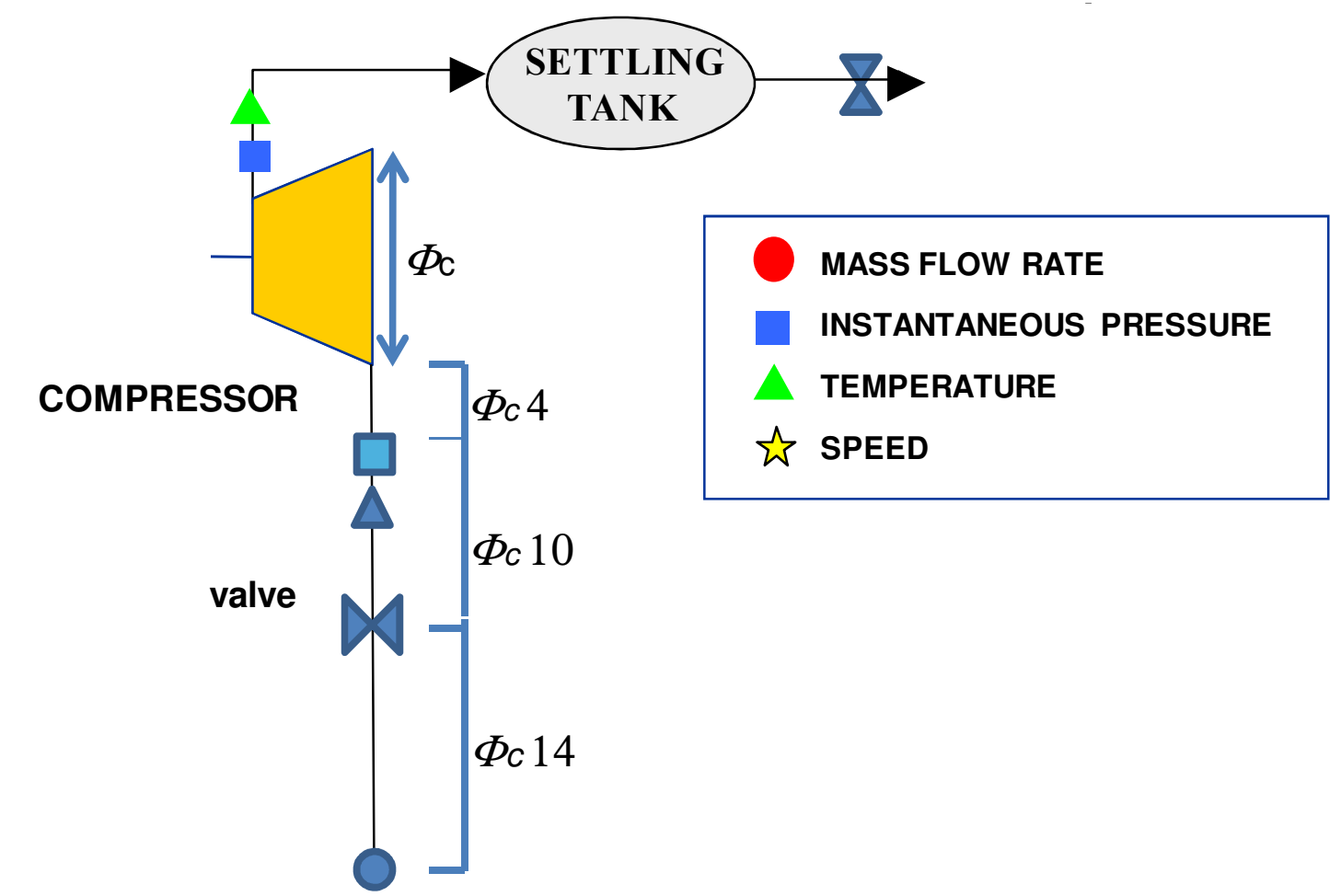

Figure 13. Experimental installation set up. 

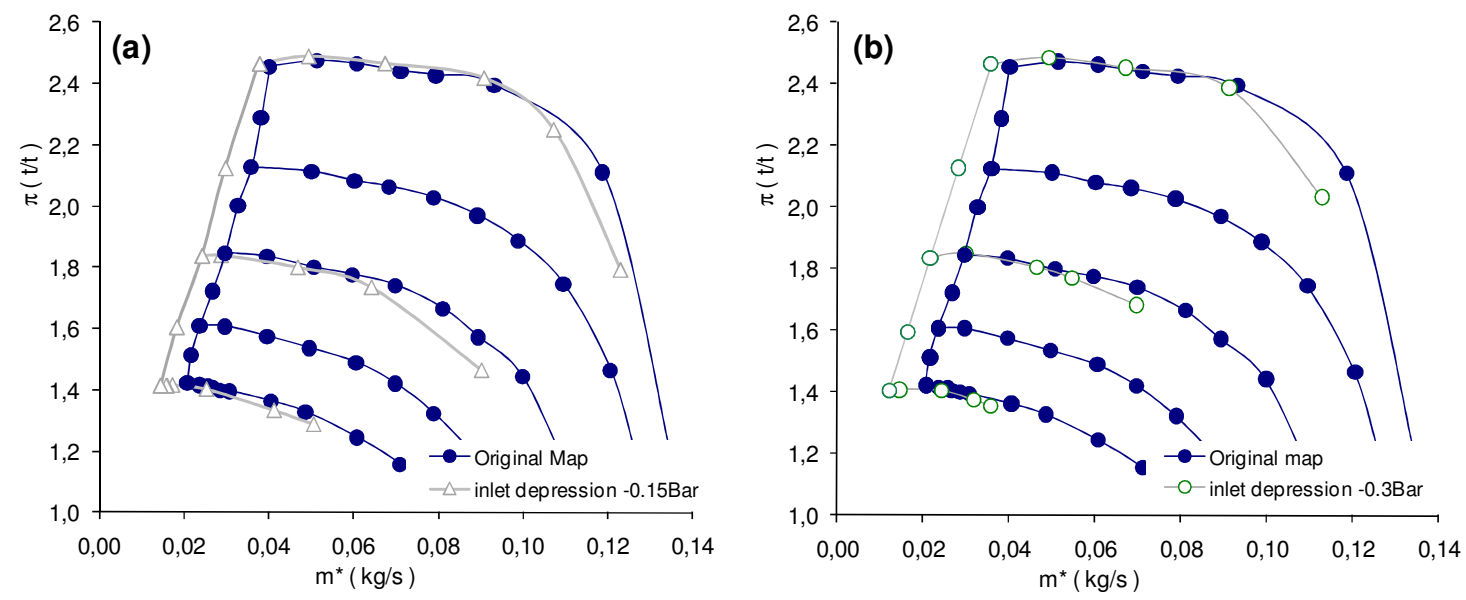

Figure 14. Original map compared with inlet depression (-0.15 and -0.3Bars) compressor map. 